\title{
A prospective randomized clinical study of thyroid hormone treatment after operations for complex congenital heart disease
}

\author{
Devyani Chowdhury, MD, Kaie Ojamaa, PhD, Vincent A. Parnell, MD, Claire McMahon, MD, Cristina P. Sison, PhD, \\ and Irwin Klein, MD, Manhasset, NY
}

I nfants and children undergoing operations for complex congenital heart disease form a group of extremely sick patients who require specialized care in the postoperative period. ${ }^{1-4}$ Treatment strategies to minimize morbidity and increase survival aim to improve cardiac function and optimize postoperative hemodynamic parameters. Changes in thyroid hormone metabolism have been documented in patients undergoing pediatric car-

\footnotetext{
From the Departments of Medicine and Pediatrics, Divisions of Pediatric Cardiology, Endocrinology and Biostatistics, North Shore-Long Island Jewish Health System, Manhasset, NY

This study was supported by National Institutes of Health Grants HL-58849 (to I.K.), HL-56804 and HL-03775 (to K.O.) and the Hutzler Fund.

Received for publication Dec 11, 2000; accepted for publication March 28, 2001.

Address for reprints: Irwin Klein, MD, Division of Endocrinology, North Shore University Hospital, 300 Community Dr, Manhasset, NY 11030 (Email: iklein@nshs.edu).

J Thorac Cardiovasc Surg 2001;122:1023-5

Copyright (C 2001 by The American Association for Thoracic Surgery

$0022-5223 / 2001 \$ 35.00+0 \quad \mathbf{1 2 / 5 4} / \mathbf{1 1 6 1 9 2}$

doi:10.1067/mtc.2001.116192
}

diac surgery, as well as in adult patients. ${ }^{1-6} \mathrm{~A}$ recent study in children undergoing cardiac surgery who received a single daily bolus dose of triiodothyronine $\left(\mathrm{T}_{3}\right)$ in the postoperative period showed significant improvement in cardiac function and decreased postoperative therapeutic intervention, especially in those patients undergoing more complex surgical procedures. ${ }^{6}$ The present report is the first prospective randomized study to use a continuous infusion protocol to achieve normal steady-state serum $\mathrm{T}_{3}$ levels in children for up to 7 days after cardiac surgery and to assess clinical outcomes.

\section{Methods}

We evaluated 75 consecutive patients of either sex undergoing cardiac surgery between the ages of birth and 18 years. The protocol was approved by the institution's committee on human rights in research. Parents or guardians gave informed consent before the operation, and patients older than 7 years of age gave assent.

Serum thyroid hormone levels were measured preoperatively, immediately postoperatively, and then once a day. Criteria for assignment to the treatment arm of the study included a serum total $\mathrm{T}_{3}$ level of less than $40 \mathrm{ng} / \mathrm{dL}$ (or $<60 \mathrm{ng} / \mathrm{dL}$ for newborns) on postoperative days 0,1 , or 2 and a requirement for mechanical ventilation. Patients randomized to the $T_{3}$ treatment group received continuous $T_{3}$ infusion at 0.05 to $0.15 \mu \mathrm{g} / \mathrm{kg}$ of body 


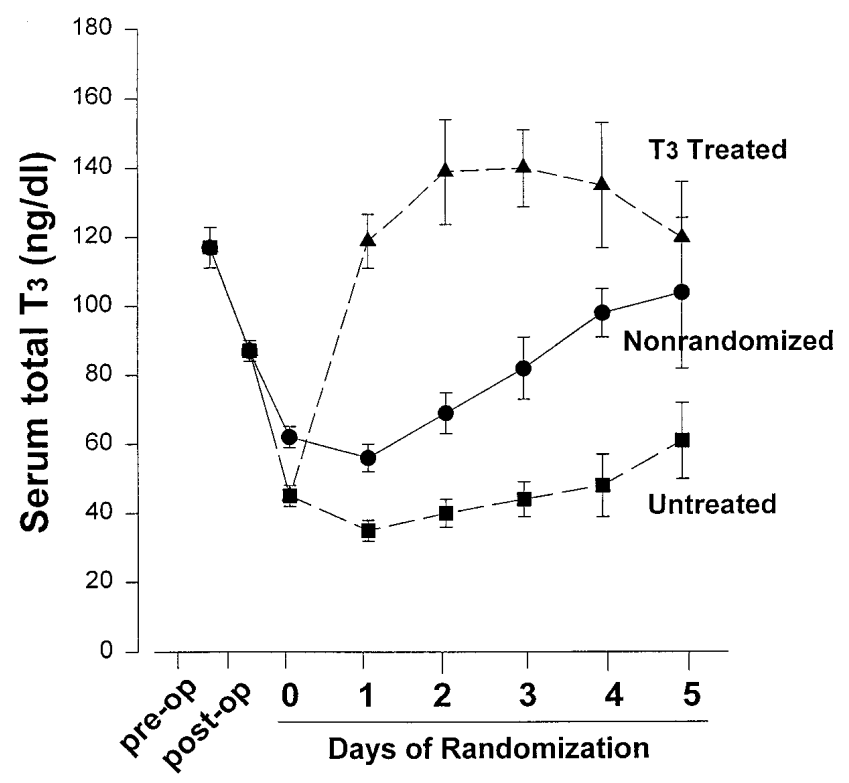

Figure 1. Preoperative and postoperative serum total $T_{3}$ levels in pediatric patients undergoing operations for congenital heart disease. Mean \pm SE serum total $T_{3}$ concentrations in all study patients who were randomized to the $T_{3}$-treated $(n=14)$ or the untreated ( $n=14$ ) groups or were not eligible for randomization (nonrandomized group, $n=47$ ) are shown. Preoperative serum samples were drawn in the operating room after induction of anesthesia. Postoperative serum samples were drawn immediately after the operation. Day 0 of randomization into the study represents serum total $T_{3}$ values obtained 24 to 48 hours after the operation. To convert values for $T_{3}$ to nanomoles per liter, multiply by 0.015 . All data points between postoperative day 1 and 5 are significantly different among the 3 groups $(P<.05)$.

weight per hour to maintain serum levels within the normal range (80-200 ng/dL). ${ }^{4}$ Serum thyrotropin levels were analyzed to ensure that the treatment dose did not render the patient chemically hyperthyroid.

The degree of inotropic support required was calculated as previously described by Wernovsky and colleagues. ${ }^{7}$ Cardiac rhythm was continuously monitored with bedside monitors and telemetry. The overall degree of postoperative care was analyzed by calculating the Therapeutic Interventional Scoring System (TISS) score. Scores were given for 76 different therapeutic and monitoring procedures and reflected the invasiveness, intensity, and complexity of care rendered to the patient. ${ }^{4,6}$

All demographic, baseline, and outcome variables were compared by the Mann-Whitney test. Categoric variables were compared by the Fisher exact test. Results are expressed as means \pm standard deviation. A 2-factor repeated-measures analysis of variance with group and day as the main effects and including the interaction effect (group $\times$ day) in the model was initially carried out for the serum $\mathrm{T}_{3}$ level. Bonferroni-adjusted pairwise comparisons between days were carried out.

\section{Results}

Twenty-eight of 75 patients were eligible for the study, with 14 patients randomized to $\mathrm{T}_{3}$ treatment. Figure 1 shows serum total $\mathrm{T}_{3}$ levels preoperatively and postoperatively in all study patients. Serum $\mathrm{T}_{3}$ levels fell in all patients after operations with the lowest values consistently measured after 24 and 48 hours. Patients receiving continuous $T_{3}$ infusion achieved serum $T_{3}$ values equivalent to the mean preoperative levels within 24 hours of initiation of treatment. Of the 28 study patients, serum $\mathrm{T}_{3}$ levels were equivalent at the time of randomization. $\mathrm{T}_{3}$ treatment did not alter outcome measures in the randomized groups when all 28 patients were considered (Table 1). No differences were found for TISS score, inotropic score, or dose requirements for milrinone and furosemide. Similarly, no significant differences were measured between the 2 groups for days of mechanical ventilation or length of hospital stay.

Nine patients within the overall study group were newborns $\left(<1\right.$ month of age); 5 were randomized to $\mathrm{T}_{3}$ treatment and 4 to the untreated group (Table 1). No significant differences between the $\mathrm{T}_{3}$-treated and untreated newborns were found with respect to the number of patients requiring cardiopulmonary bypass, the total bypass time, duration of crossclamping, and duration of hypothermic cardiac arrest. Twenty-four hours after initiation of $\mathrm{T}_{3}$ treatment, the serum total $\mathrm{T}_{3}$ level was restored to normal at $130 \pm 38$ $\mathrm{ng} / \mathrm{dL}$, which was significantly higher than the level of $34 \pm 7$ $\mathrm{ng} / \mathrm{dL}$ found in the untreated group.

The TISS score was not different on day 0 of randomization, but on randomization days 1,2 , and 3 , scores were significantly lower $(P=.037)$ in the $\mathrm{T}_{3}$-treated group $(40 \pm 7 \mathrm{ng} / \mathrm{dL})$ compared with the untreated group $(49 \pm 3 \mathrm{ng} / \mathrm{dL})$, indicating lower postoperative management requirements (Table 1 ). $\mathrm{T}_{3}$ treatment significantly decreased the need for inotropic support, as documented by a lower mean daily inotropic score of $5 \pm 3$ compared with $23 \pm$ $26(P=.037)$ in the untreated group (Table 1$)$. Mixed venous oxygen saturation $\left(\mathrm{MVO}_{2}\right)$ values were obtained in 8 newborns. The mean $\mathrm{MVO}_{2}$ values at the time of randomization were similar at $53 \% \pm 13 \%$ and $42 \% \pm 10 \%$ for the $\mathrm{T}_{3}$-treated and untreated patient groups, respectively. After 18 to 24 hours, the mean $\mathrm{MVO}_{2}$ increased to $70 \% \pm 12 \%$ in the $\mathrm{T}_{3}$-treated group and remained unchanged at $44 \% \pm 18 \%$ in the untreated group. These differences, however, did not reach statistical significance because of the small sample size. Although the length of hospital stay and days of mechanical ventilation were not significantly different between the 2 groups, the mean values showed a trend toward shorter times in the $\mathrm{T}_{3}$-treated group (Table 1 ).

\section{Discussion}

Previous studies in adult ${ }^{5}$ and pediatric heart surgery patients ${ }^{1-4,6,8}$ have reported alterations in thyroid hormone metabolism, leading to significant decreases in postoperative serum total $\mathrm{T}_{3}$ levels and normal or reduced serum thyrotropin and thyroxine levels. A recent study showed that the half-life of serum $\mathrm{T}_{3}$ in children after heart surgery was markedly decreased. ${ }^{9}$ Bettendorf and colleagues ${ }^{1,6}$ reported that a low serum $\mathrm{T}_{3}$ level in children after cardiac surgery was a predictor of adverse outcome and that $\mathrm{T}_{3}$ treatment significantly improved cardiac function. Because we and others have shown that thyroid hormones have both inotropic and vasoactive effects, ${ }^{10}$ we undertook a study to determine 
TABLE 1. Characteristics and treatment outcomes of the $T_{3}$ study patients

\begin{tabular}{lccc}
\hline & Untreated & T $_{\mathbf{3}}$ treatment & P value \\
\hline Overall study groups & & & 14 \\
No. of patients & 14 & $1.3 \pm 2.4$ & 1.000 \\
Age (y) & $3.2 \pm 5.1$ & $39 \pm 12$ & .765 \\
TISS* & $36 \pm 12$ & $8 \pm 4$ & .696 \\
Inotropic score* & $11 \pm 2$ & $4 \pm 2$ & .746 \\
Mechanical ventilation (d) & $4 \pm 3$ & $23 \pm 24$ & .747 \\
Postoperative hospital stay (d) & $24 \pm 29$ & 5 & .005 \\
Newborn patient subgroups & 4 & $4.6 \pm 2.3$ & .037 \\
No. of patients & $9.5 \pm 11.6$ & $40 \pm 7$ & .037 \\
Age (d) & $49 \pm 3$ & $5 \pm 3$ & .171 \\
TISS* & $23 \pm 26$ & $4 \pm 2$ & .109 \\
Inotropic score* & $6 \pm 2$ & $18 \pm 17$ & \\
Mechanical ventilation (d) & $56 \pm 38$ & & \\
Postoperative hospital stay (d) & &
\end{tabular}

Values are listed as means $\pm S D$ where shown. The normal range for serum total $T_{3}$ is 80 to $200 \mathrm{ng} / \mathrm{dL}(1.2-3.0 \mathrm{nmol} / \mathrm{L})$.

*Mean daily postrandomization score.

whether $\mathrm{T}_{3}$ replacement by continuous infusion of pediatric patients after cardiac surgery would improve clinical outcome. Evaluation of 75 patients showed that serum total $\mathrm{T}_{3}$ levels fell predictably within 72 hours of the operation to a mean nadir value of $42 \pm 13 \mathrm{ng} / \mathrm{dL}$. The present data are in agreement with the results reported by Mainwaring, ${ }^{2}$ Bettendorf, $, 1,6$ and their colleagues, who showed that the fall in serum $\mathrm{T}_{3}$ was greater in patients undergoing complex cardiac surgical procedures. In the present study $\mathrm{T}_{3}$ treatment was accomplished safely with no untoward changes in blood pressure, heart rate, or cardiac rhythm. $\mathrm{T}_{3}$ treatment of the overall study group did not significantly alter postoperative outcome measures, including the TISS, days of mechanical ventilation, or overall length of hospital stay. In contrast, newborn patients showed the tendency for a positive therapeutic response to $\mathrm{T}_{3}$ treatment, as indicated by a significantly lower TISS score and lower inotropic requirements that persisted throughout the randomization period. As a measure of cardiac output and peripheral perfusion, the $\mathrm{MVO}_{2}$ measurements in the newborns showed a $17 \%$ increase after $\mathrm{T}_{3}$ treatment compared with a $2 \%$ increase in the untreated group.

This positive postoperative outcome can be explained in part by the known molecular effects of thyroid hormone to increase cardiac contractility and to lower systemic vascular resistance in cardiac disease, ${ }^{10}$ after cardiac surgery, ${ }^{4-6}$ and in the low- $\mathrm{T}_{3}$ syndrome. ${ }^{10}$ In conclusion, the present data suggest a therapeutic benefit of $\mathrm{T}_{3}$ in the postoperative period by using a continuous infusion protocol to normalize serum $\mathrm{T}_{3}$ levels in newborn patients undergoing operations for complex congenital heart disease. A prospective randomized study of greater statistical power will be required to confirm these results.

\section{References}

1. Bettendorf M, Schmidt KG, Tiefenbasher U, Grulich-Henn J, Heinrich UE, Schonberg DK. Transient secondary hypothyroidism in children after cardiac surgery. Pediatr Res. 1997;41:375-9.

2. Mainwaring RD, Lamberti JJ, Carter TL, Nelson JC. Reduction in triiodothyronine levels following modified Fontan procedure. J Card Surg. 1994;9:322-31.

3. Murzi B, Iervasi G, Masini S, Moschetti R, Vanini V, Zuchelli G. Thyroid hormone homeostasis in pediatric patients during and after cardiopulmonary bypass. Ann Thorac Surg. 1995;59:481-5.

4. Chowdhury D, Parnell VA, Ojamaa K, Boxer R, Cooper R, Klein I Usefulness of triiodothyronine $\left(\mathrm{T}_{3}\right)$ treatment after surgery for complex congenital heart disease in infants and children. Am J Cardiol. 1999;84:1107-9.

5. Klemperer JD, Klein I, Gomez M, Helm RE, Ojamaa K, Thomas SJ, et al. Thyroid hormone treatment after coronary-artery bypass surgery. N Engl J Med. 1995;333:1522-7.

6. Bettendorf M, Schmidt KG, Grulich-Henn J, Ulmer HE, Heinrich UE. Tri-iodothyronine treatment in children after cardiac surgery: a double-blind, randomised, placebo-controlled study. Lancet. 2000;356: 529-34.

7. Wernovsky G, Wypij D, Jonas RA, Mayer JE Jr, Hanley FL, Hickey PR, et al. Postoperative course and hemodynamic profile after the arterial switch operation in neonates and infants: a comparison of lowflow cardiopulmonary bypass and circulatory arrest. Circulation. 1995;92:2226-35.

8. Mainwaring RD, Capparelli E, Schell K, Acosta M, Nelson JC. Pharmacokinetic evaluation of triiodothyronine supplementation in children after modified Fontan procedure. Circulation. 2000;101: 1423-9.

9. Portman MA, Fearneyhough C, Ning XH, Duncan BW, Rosenthal GL, Lupinetti FM. Triiodothyronine repletion in infants during cardiopulmonary bypass for congenital heart disease. $J$ Thorac Cardiovasc Surg. 2000;120:604-8.

10. Klein I, Ojamaa K. Mechanisms of disease: thyroid hormone and the cardiovascular system. $N$ Engl J Med. 2001;344:501-9. 